\title{
Visual acuity measurements in a national sample of British elderly people
}

\author{
J C van der Pols, C J Bates, P V McGraw, J R Thompson, M Reacher, A Prentice, S Finch
}

MRC Human

Nutrition Research,

Cambridge CB4 1XJ

J C van der Pols

C J Bates

A Prentice

University of

Bradford, Department of Optometry, Bradford BD7 1DP

P V McGraw

Leicester Royal Infirmary/University of Leicester, Ophthalmology Department, Leicester LE2 7LX

J R Thompson

Public Health Laboratory Service, London NW9 5EQ

M Reacher

Social and Community Planning Research, London EC1V 0ED $S$ Finch

Correspondence to: Miss Jolieke van der Pols, MRC Human Nutrition Research, Downham's Lane, Milton Road, Cambridge CB4 1XJ

Accepted for publication 11 August 1999

\begin{abstract}
Background-Despite the fact that visual function has an important role in the quality of life in later years, very few studies have measured visual acuity in population based nationwide samples of British elderly people. Such measurements were carried out in the context of the national diet and nutrition survey of people aged 65 years or over (NDNS).

Methods-NDNS participants, who were living in 80 different randomly selected postcode areas of mainland Britain, were visited at their home by a nurse who measured visual acuity at 3 metres, using the Glasgow acuity card (GAC) method. In addition, a brief questionnaire related to ocular health was administered.

Results-Visual acuity was measured in 1362 NDNS participants who were not classified as mentally impaired. Visual impairment (using the WHO low vision criteria) was measured in 195 (14.3\%) subjects. Prevalence of visual impairment increased significantly with age (65-74 years $3.1 \%$; $75-84$ years $11.6 \%$; $85+$ years $35.5 \%, p<0.001$ for trend). Impaired vision was more common in subjects living in a nursing home (odds ratio adjusted for age $2.59(95 \%$ CI 2.23 to 2.96$)$ ) and in women (odds ratio adjusted for age 1.55 (95\% CI 1.21 to 1.89$)) .132(9.7 \%)$ subjects had previously undergone cataract surgery and another $157(11.5 \%)$ had been told that they currently had cataract. Vision improved $0.2 \mathrm{log}$ units or more (at least one Snellen line) with the aid of a pinhole occluder in 289 subjects $(21.2 \%)$.

Conclusion-Results of this nationwide, community based study confirm that problems with poor distance visual acuity exist in a substantial part of the elderly community, particularly in women and people living in nursing homes.

(Br F Ophthalmol 2000;84:165-170)
\end{abstract}

Although visual function is known to have an important role in the quality of life in elderly populations, ${ }^{1-4}$ very few studies have measured visual acuity in representative population based samples of British elderly people. Moreover, housebound elderly and people living in nursing homes have not been included in most studies. Prevalence data of visual impairment are extremely important for the adequate planning of services for this age group. ${ }^{5}$

A unique opportunity to study visual acuity in a nationwide random sample of British elderly people arose in the context of the national diet and nutrition survey of people aged 65 years or over. Because measurements were carried out at the subject's home and in nursing homes, frail and immobile people could also be included in the study.

This paper presents the prevalence of visual impairment in survey participants and evaluates the feasibility of the Glasgow acuity card method in a community based study of visual acuity.

\section{Methods}

NATIONAL DIET AND NUTRITION SURVEY

The national diet and nutrition survey: people aged 65 years or over (NDNS) aimed to recruit a representative sample of men and women aged 65 years or over, from 80 different randomly selected postcode sectors of mainland Britain. The chance for each postcode sector to be selected was proportional to its size. Within each sector, randomly selected private households were sent a sift form which asked for details of the name, age, and sex of all household members. The manager of eligible residential nursing homes (not geriatric hospitals) was approached to introduce the survey and make a list of residents. A random sample of eligible individuals was selected using probabilities required to produce suitable numbers for statistical comparisons in each sex and age group (65-74 years, $75-84$ years, and 85 years and over), with only one person being sampled per private household and three people in each nursing home. Seventy five per cent of the free living eligible subjects cooperated with the main survey questionnaire and $94 \%$ of the institution sample, resulting in 2060 NDNS participants in total. Further details on subject selection and procedures are presented in the official survey report. ${ }^{6}$

Fieldwork for the survey was carried out in 1994/5. Ethical approval was given by all 65 NHS local research ethics committees involved, and by the MRC Dunn Nutrition Unit ethics committee.

All survey participants were initially visited by an interviewer who administered a questionnaire related to diet and health. Questions regarding socioeconomic status, sight problems, and use of spectacles were included in this main questionnaire. A short memory questionnaire $^{7}$ was administered in order to detect mental impairment and the need for proxy consent. Within 2-3 weeks after the interview, participants were visited by a nurse, who, as part of an add-on component to the main survey activities, measured distance visual acuity. 
Table 1 Comparison of different visual acuity scoring systems

\begin{tabular}{llll}
\hline$G A C^{*}$ & Snellen (UK) & $\begin{array}{l}\text { Snellen } \\
\text { (USA) }\end{array}$ & $\log M A R$ \\
\hline 0.125 & $6 / 45$ & $20 / 150$ & 0.875 \\
0.2 & $6 / 38$ & $20 / 127$ & 0.8 \\
0.3 & $6 / 30$ & $20 / 100$ & 0.7 \\
0.4 & $6 / 24$ & $20 / 80$ & 0.6 \\
0.5 & $6 / 19$ & $20 / 63$ & 0.5 \\
0.6 & $6 / 15$ & $20 / 50$ & 0.4 \\
0.7 & $6 / 12$ & $20 / 40$ & 0.3 \\
0.8 & $6 / 9.5$ & $20 / 32$ & 0.2 \\
0.9 & $6 / 7.5$ & $20 / 25$ & 0.1 \\
1.0 & $6 / 6$ & $20 / 20$ & 0 \\
1.1 & $6 / 5$ & $20 / 17$ & -0.1 \\
1.2 & $6 / 3.75$ & $20 / 12.5$ & -0.2 \\
1.3 & $6 / 3$ & $20 / 10$ & -0.3 \\
\hline
\end{tabular}

*Glasgow acuity cards.

\section{VISUAL ACUITY TEST}

Visual acuity was measured at 3 metres using the Glasgow acuity card method. ${ }^{8}$ This method was originally developed for use in children, but was considered to be equally appropriate in adults. It also has the advantage over the Snellen test that results are amenable to simple mathematical treatment. All nurses were instructed in the use of the method during a special group training and practice session.

The Glasgow acuity card (GAC) method uses 12 different cards, each displaying a line of four different, equally sized letters of the alphabet. Each of the letters (from a group of six) are approximately equal in legibility. Each successive test card represents a 0.1 log unit change in acuity level (angle subtended) with each letter correctly identified adding a value of $0.025 \mathrm{log}$ unit. This regular geometric progression of letter sizes offers the advantage that a simple mathematical adjustment can be applied to correct for varying test distances. A $0.1 \log$ unit reduction in test distance will cause a 0.1 log unit increase in angular size of

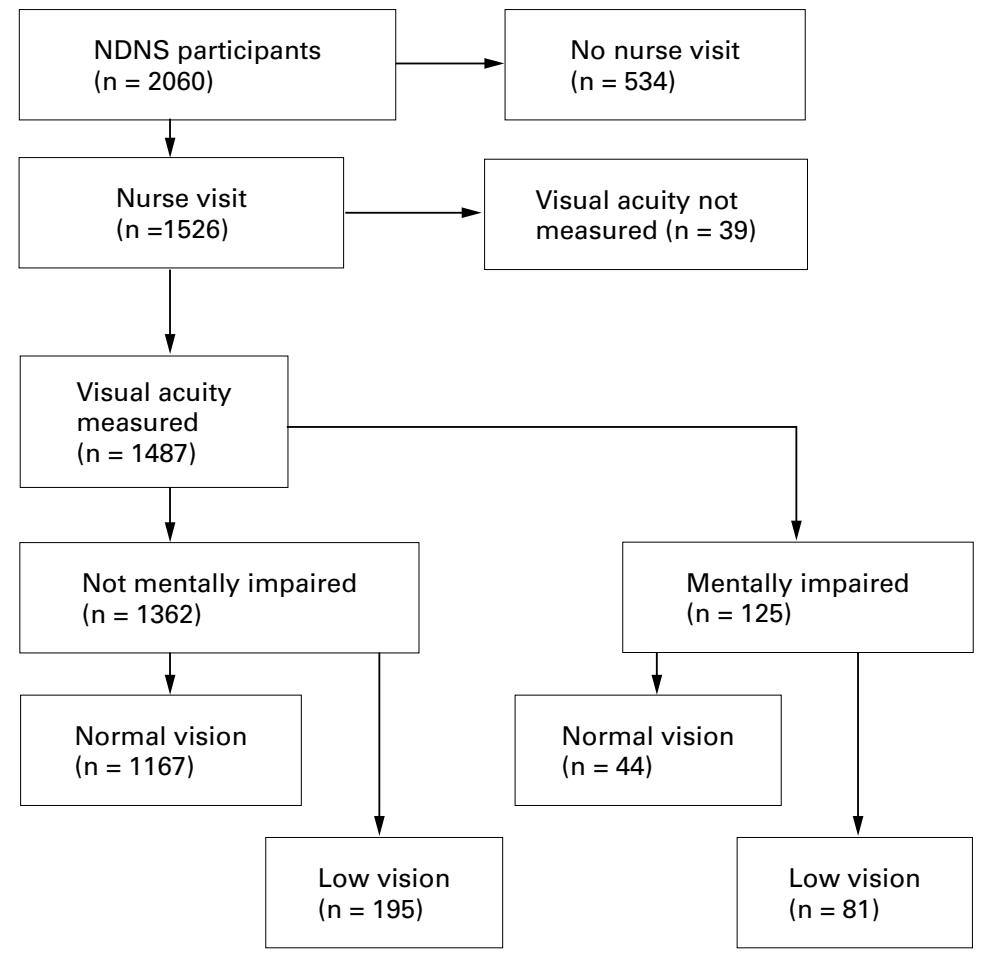

Figure 1 Sample size and characteristics. the letters. ${ }^{89}$ In situations where the 3 metres distance could not be achieved because of room size limitations, the reduced test distance was recorded and a corrected visual acuity score was calculated.

The possible scores at 3 metres test distance range from 0.125 to 1.3 , which corresponds with $6 / 45$ to $6 / 3$ Snellen score (Table 1 ). Vision worse than 0.125 at 3 metres distance was not measured because of time restrictions. Subjects with a GAC acuity score of poorer than 0.125 were included in the analyses as being visually impaired according to both the WHO and US criteria.

Visual acuity was measured for each eye separately, first without correction, then with a pinhole occluder. If the subject normally used spectacles for distance vision the measurements were repeated, first with spectacles and then with spectacles plus the pinhole occluder. The highest GAC score from any of the measurements in the better eye is defined here as the best visual acuity.

If a person needs refractive correction, the corrected acuity can be estimated by testing vision through a pinhole occluder. ${ }^{10}$ We considered a subject to have a possible need for further refraction, and thus for first time spectacles or a revised prescription, when the test result with the pinhole occluder exceeded the result without the occluder by $0.2 \mathrm{log}$ unit or more. This is equivalent to an improvement of at least one line on a Snellen chart or a decrease of $0.2 \log$ MAR (a one line change on a Snellen chart represents on average a change of $0.154 \log$ units).

Following the visual acuity test, the nurse administered a brief questionnaire related to ocular health.

VISUAL IMPAIRMENT

Low vision is defined by the WHO (World Health Organisation) criteria as visual acuity less than $6 / 18$ in the better eye ${ }^{11}$; subjects in this study were considered to have low vision as defined by WHO if their best visual acuity was equal to or below 0.5 GAC score (6/19 Snellen equivalent, see Table 1). Visual impairment according to US criteria is best acuity of less than $6 / 12$ and better than $6 / 60^{12}$; subjects in this study were considered to have visual impairment according to US criteria if their best visual acuity was below 0.7 GAC score (6/12 Snellen equivalent, see Table 1).

\section{STATISTICS}

The $\chi^{2}$ test was used to study relations between discrete variables. Subgroups of continuous variables were compared by an independent sample $t$ test. The Mantel-Haenzel test for linear association ${ }^{13}$ was used to assess linear trends. Logistic regression analysis was used to calculate odds ratios (OR) with 95\% confidence intervals.

\section{Results}

VISUAL IMPAIRMENT

Visual acuity was successfully measured in $97.4 \%(1487 / 1526)$ of all NDNS participants who agreed to a visit by a nurse (Fig 1). Eleven 
Table 2 Characteristics of the sample

\begin{tabular}{|c|c|c|c|c|}
\hline & $\begin{array}{l}\text { Visual acuity } \\
\text { measured }\end{array}$ & $\begin{array}{l}\text { Visual acuity not } \\
\text { measured }\end{array}$ & $\begin{array}{l}\text { NDNS participants } \\
\text { visited by a nurse }\end{array}$ & $\begin{array}{l}\text { NDNS participants } \\
\text { not visited by a nurse }\end{array}$ \\
\hline Number & 1487 & 39 & 1526 & 534 \\
\hline \multirow[t]{2}{*}{ Age mean (SD) } & $78.2(8.0) \S$ & $82.9(8.3) \S$ & $78.3(8.0) \S$ & $79.7(8.0) \S$ \\
\hline & $\%$ & $\%$ & $\%$ & $\%$ \\
\hline Female & 49.25 & 64.15 & $49.5 \rrbracket$ & $63.5 \rrbracket$ \\
\hline Living in an institution & $22.6 \$$ & $69.2 \S$ & $23.8 \AA$ & $12.2 \Omega$ \\
\hline Education level, secondary or higher & 38.9 & 18.2 & $38.7 \S$ & $27.2 \Omega$ \\
\hline Social class non-manual & 44.9 & 38.7 & 44.8 & $38.7 \AA^{\natural}$ \\
\hline Sight problems^ & 28.7 & 30.8 & $28.8 \rrbracket$ & $25.7 \S$ \\
\hline Using spectacles† & $92.7 \S$ & $71.8 \Phi$ & $92.2 \$$ & $84.6 \$$ \\
\hline
\end{tabular}

^Answered 'yes" to the question "Does your sight ever cause you difficulties, even when you are wearing your glasses or contact lenses?”

†Answered "yes" to the question "Do you ever wear glasses or contact lenses?"

\p<0.05.

ऽ $\leqslant 0.001$.

subjects $(11 / 1487=0.8 \%)$ were of non-white racial origin (five black Caribbean/African, three Indian, three other or mixed).

Visual acuity was not measured in 39 subjects who were too tired from the preceding measurements or who had other obligations and consequently could not complete all components of the nurse visit. These 39 subjects were older and more commonly living in an institution (Table 2).

NDNS participants who did not consent to a visit by a nurse, which was arranged primarily for phlebotomy and anthropometric measurements, were more often female and more often living in their own home than the subjects who agreed to a nurse visit. They were less likely to have completed secondary education or above and were less likely to be of non-manual social class (Table 2). The racial origin of these subjects was comparable with that of subjects who completed the visual acuity measurements (0.8\% non-white).

Visual acuity was measured in 125 subjects $(125 / 1487=8.4 \%)$ who were classified as mentally impaired by a memory test. These subjects will be discussed separately.

During the visual acuity tests, 825 subjects $(825 / 1362=60.6 \%)$ used spectacles for dis- tance vision. In nine cases the 3 metre test distance could not be achieved owing to room limitations and a corrected visual acuity score was calculated. The test distance was never shorter than 2 metres. Most subjects (1212/ $1362=89.0 \%$ ) reported that they used reading glasses. Subjects who reported using spectacles agreed more often to the nurse visit and more often completed the visual acuity measurements than those who did not use spectacles (Table 2).

Almost $10 \%$ of the subjects (132/1362 $=9.7 \%$ ) reported that they had undergone cataract surgery on one or both eyes in the past; 157 other subjects $(11.5 \%)$ had been told by a doctor or optician that they currently had a cataract; 60 subjects $(4.4 \%)$ were registered as blind or partially sighted. Almost half of the subjects $(610 / 1362=44.8 \%)$ reported that they had had an eye test in the 12 months before the interview.

Table 3 presents the prevalence of visual impairment in the 1362 subjects from whom visual acuity scores were successfully measured and who were not classified as mentally impaired. Overall, 195 subjects (195/1362 $=14.3 \%$ ) had low vision according to the WHO criteria.

Table 3 Visual impairment in NDNS subjects according to WHO and USA criteria in different age, domicile, and sex groups

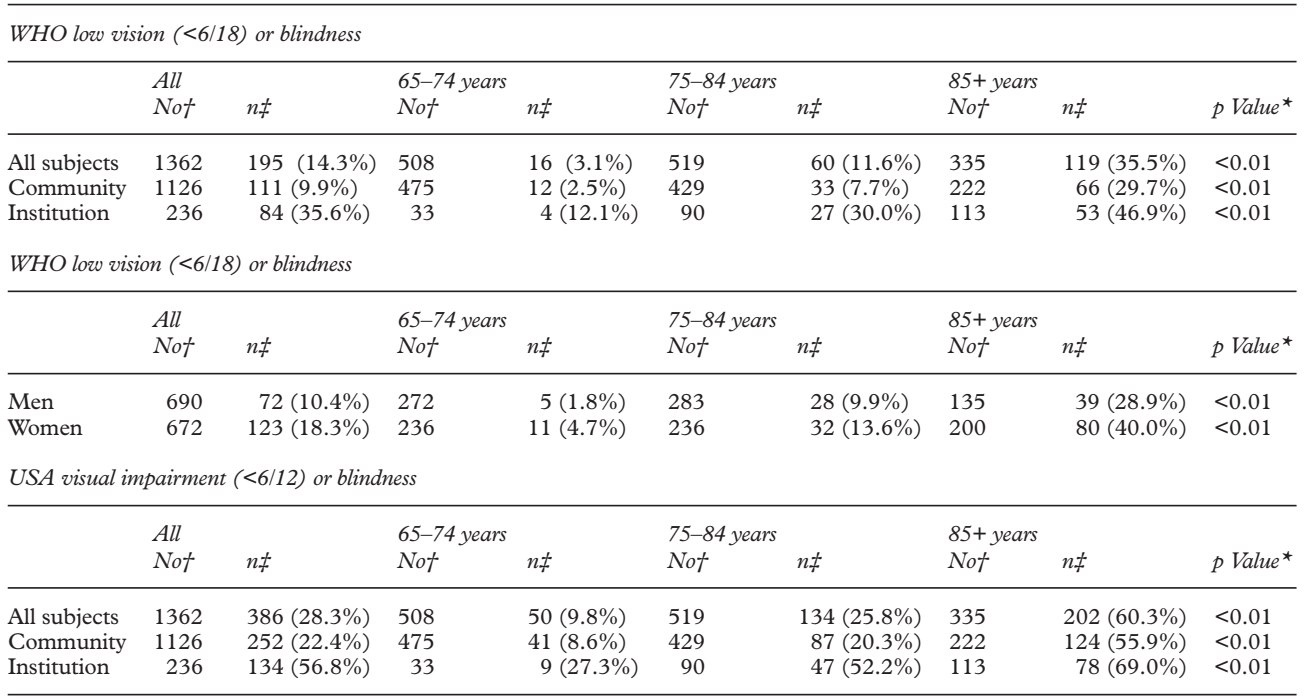

†Total number of subjects measured in that group.

$\ddagger$ Number of subjects in that group who were visually impaired.

${ }_{\star}$ Mantel-Haenzel test for linear association. 
Visual impairment shows, as expected, a strong positive linear trend with age. Logistic regression of the WHO low vision, corrected for age as a continuous variable, confirms the higher risk of visual impairment in subjects living in an institution $\left(\mathrm{OR}_{\mathrm{adj}}=2.59(95 \%\right.$ confidence interval 2.23 to 2.96$)$ ) and in women $\left(\mathrm{OR}_{\mathrm{adj}}=1.55\right.$ (95\% CI 1.21 to 1.89$)$ ). No relation was observed between domicile and sex $(p=0.84)$.

If the measurements of visual impairment in the current non-mentally impaired sample were to be extrapolated to a representative sample of British elderly people aged 65 years or over, by applying the NDNS weighting factor, we would estimate the prevalence of visual impairment to be $12.0 \%$ by WHO criteria or $24.3 \%$ by US criteria.

NEED FOR (IMPROVED) SPECTACLES

In 289 subjects $(289 / 1362=21.2 \%)$ the best GAC score for either or both eyes was at least $0.2 \log$ units better when measured with a pinhole occluder than without an occluder. There were no differences in the need for spectacles between subjects living in the community and subjects living in a nursing home $(\mathrm{p}=0.16)$ or between males and females $(p=0.31)$.

MENTALLY IMPAIRED SUBJECTS

Visual acuity was successfully measured in 125 subjects who were classified as mentally impaired by a memory test. Eighty one of them $(81 / 125=64.8 \%)$ had low vision according to the WHO criteria.

\section{Discussion}

GLASGOW ACUITY CARD METHOD

The Glasgow acuity card method appears be a useful tool for the measurement of distance visual acuity at the subjects' homes. The cards are easy to use in the home, with the adjustable test distance offering an important advantage for measurements in small rooms.

Both nurses and subjects found the method easy to understand. A training session, including supervised practice of the method and comparison between scores obtained by different nurses on the same subject, instructed the nurses in the use of the method, and reduced interobserver variation.

Nurses were instructed to optimise the lighting conditions during the visual assessments; but standardisation of the light conditions was not possible, which may have somewhat influenced the measurements made. ${ }^{14}$

The prevalence estimates of visual impairment resulting from the current study agree well with estimates from other studies which have mostly used Snellen acuity charts (see below). A formal validation study of the GAC method could not be performed in the context of the NDNS survey. But a validation study in adults (mean age 21.5 years), in which the GAC method was compared with the BaileyLovie chart, showed that the average difference between the GAC and the Bailey-Lovie measurements was less than three letters $(0.067 \mathrm{log}$ unit). ${ }^{15}$ Although the Glasgow acuity card method was originally developed for use with children, these studies suggest that it has potential for wider use in other population groups and that more validation studies are warranted.

VISUAL IMPAIRMENT

The current study shows that visual impairment is commonly found in British elderly people. In particular older people living in institutions (nursing homes) and females appear to be at increased risk. The disparity of prevalence rates in males and females has also been shown in a number of other studies. ${ }^{16-18}$ Various studies have also shown high prevalence rates of vision problems in nursing home residents. ${ }^{19-21}$ This may imply that visual impairment is an unrecognised factor contributing to nursing home placement. ${ }^{192}$

The measurements of visual acuity in NDNS participants were an add-on component to the main measurements planned for the survey. Owing to the resulting restriction in time available for the visual acuity measurements, the Glasgow acuity card test could not be used to measure acuity levels below $6 / 45$. Consequently, blind subjects could not be identified. But because subjects whose vision was below $6 / 45$ were included in the estimates of visual impairment and in the further analyses, the conclusions of this study would not be different had the test level been extended.

Exclusion of NDNS participants who did not consent to a nurse visit may have caused some bias in the estimates of visual impairment prevalence. Females did not agree to the nurse visit as often as males, which may have caused some bias towards better vision levels. However, subjects who reported problems with their eyesight were more often included than those who did not report such problems.

Nursing home residents were more often included than independently living subjects. This would have biased the overall estimated prevalence rates towards worse vision levels because of the observed higher prevalence of visual impairment in people living in institutions. The impact of this selection bias is greatly reduced by the application of the weighting factor which takes oversampling of people in institutions into consideration.

Three regional random sample, cross sectional population surveys have been carried out in Britain. They examined community residents (75+ years) of Melton Mowbray, Leicestershire, ${ }^{16}$ patients (65+ years) from an inner London health centre, ${ }^{23}$ and elderly people (65+ years) registered with 17 general practice groups in north London. ${ }^{24}$ These studies found that bilateral visual impairment or blindness existed in $26 \%(\leqslant 6 / 18), 15 \%(<6 /$ $12)$, and $30 \%(<6 / 12)$ of the participants respectively. Both the Melton Mowbray and inner London heath centre study offered the opportunity for the eye examinations to be carried out at the subject's home.

The prevalence of visual impairment varies widely from one study to another depending on definitions of impairment and the nature of the population being studied. ${ }^{5}$ In particular the 
age distribution of a sample strongly affects the overall estimate of visual impairment. The prevalence estimates from the Melton Mowbray and inner London health centre studies compare favourably with our results $(28 \%$ $<6 / 18$ and $14 \%<6 / 12$ ). However, the age distribution of our sample is best comparable with the Melton Mowbray and north London studies. The inner London study did not include as many very old people as the NDNS survey. The characteristics of the NDNS subjects, which included people from both rural and urban areas, were possibly on average more comparable with those of the Melton Mowbray subjects than of the urban north London sample. In correspondence with our data, all three studies showed a higher prevalence of visual impairment or eye disease in women.

The national survey of visually disabled people in England and Wales ${ }^{25}$ also measured visual acuity at the home of members of randomly selected households. However, only subjects who reported vision problems were assessed. This survey ${ }^{25}$ estimated that $13 \%$ of people in one person households aged 60 or over were visually impaired $(\leqslant 6 / 24)$. Comparison with NDNS results are problematic since not all participants of this 1977 survey had visual acuity measured.

Two other studies examined patients visiting hospital clinics. ${ }^{26}{ }^{27}$ Unfortunately, these studies are affected by selection bias as they are based only on subjects in poor health, like the hospital based blind and partially sighted survey in the United Kingdom. ${ }^{28}$ Therefore the results cannot be extrapolated to the general population.

International comparisons are possible with some purposely designed population based studies of eye disease in older adults. Table 4 shows the prevalence estimates resulting from the American Beaver Dam eye study ${ }^{29}$ and the Australian Blue Mountain eye study ${ }^{17}$ and the Melbourne visual impairment project. ${ }^{18} \mathrm{Be}-$ cause the Australian studies included elderly people living in the community only and nursing home residents were making up only $1 \%$ of the Beaver Dam eye study population, comparisons with estimates from the NDNS community sample are appropriate.

Both the Melbourne visual impairment project and the Beaver Dam eye study offered participants the possibility to carry out the measurements at home. But the fact that all participants in the NDNS were visited at home may have selected relatively more fragile subjects, which may have resulted in the comparatively higher prevalence rates of visual impairment. The non-standardised lighting conditions (as discussed above) may also

Table 4 International comparison of visual impairment $<6 / 18$ (including blindness) estimates

\begin{tabular}{|c|c|c|c|c|}
\hline Age category & $\begin{array}{l}\text { NDNS community } \\
\text { sample }\end{array}$ & $\begin{array}{l}\text { Blue Mountains } \\
\text { eye study }{ }^{17}\end{array}$ & $\begin{array}{l}\text { Beaver Dam eye } \\
\text { study }\end{array}$ & $\begin{array}{l}\text { Melbourne visual } \\
\text { impairment project }\end{array}$ \\
\hline $65-74$ years & $2.5 \%$ & $0.3 \%$ & $0.7 \%$ & $1.2 \%(60-70$ years $)$ \\
\hline $75-84$ years & $7.7 \%$ & $3.2 \%$ & $6.0 \%$ & $2.5 \%(70-80$ years $)$ \\
\hline $85+$ years & $29.7 \%$ & $13.6 \%$ & not included & $11.8 \%(80+$ years $)$ \\
\hline
\end{tabular}

contribute to the high estimates resulting from our study.

Our estimates in institutionalised subjects compare well with the measurements of nursing home residents in the Blue Mountain eye study, where the prevalence of visual impairment including blindness ranged from $12 \%$ in subjects between 50 and 70 years old to $55 \%$ in the over 90 years old ${ }^{19}$

\section{NEED FOR SPECTACLES}

The pinhole aided measurements highlighted a possible need for (improved) refractive correction in $22.6 \%$ of a national sample of British elderly people. This is in keeping with similar measurement performed by Wormald et al in a study of elderly people living in central London, where $27 \%$ of the subjects showed a one line improvement in distance visual acuity with the aid of a pinhole..$^{23}$ The improvement in visual acuity when using a pinhole occluder indicates that the factor impairing or limiting visual function is optical in nature rather than retinal or neural. The most likely source of optical impairment is uncorrected refractive error, besides possible media opacification. It is likely that many of these subjects would benefit from a full refraction and revised refractive prescription.

MENTALLY IMPAIRED SUBJECTS

An attempt was made to measure visual acuity in mentally impaired NDNS survey participants. As expected, the prevalence of visual impairment was high in these subjects. However, it is unclear to what extent true visual disorders are responsible and to what extent the poor mental capacity of these subjects influenced the measurements results. Further study of the measurement of vision and the role of visual function in the wellbeing of mentally impaired elderly will be needed to determine the needs of this vulnerable population group.

In summary, we conclude that problems with poor distance visual acuity exist in a substantial part of the elderly community, particularly in women and those living in nursing homes. Undetected refractive errors are probably an important cause of visual problems in British elderly people.

The authors thank Michael Whitelaw and Steve Austin for their contributions to training of the nurses. Jolieke $\mathrm{C}$ van der Pols is receiving a research training grant from the European Commission DG-XII. Paul V McGraw is supported by the Wellcome sion DG-XII. Paul V McGraw is supported by the Wellcome
Trust. The national diet and nutrition survey of people aged 65 Trust. The national diet and nutrition survey of people aged 65
years or over was funded jointly by the Ministry of Agriculture, years or over was funded jointly by the Ministry of Agriculture,
Fisheries and Food and the Department of Health, and Fisheries and Food and the Department of Health, and
conducted by Social and Community Planning Research, in conjunction with the Medical Research Council's Dunn Nutrition Unit. Visual acuity measurements were funded by the Department of Health and the Medical Research Council.

1 Lee PP, Spitzer K, Hays RD. The impact of blurred vision on functioning and well-being. Ophthalmology 1997; 104:390-6.

2 Salive M, Guralnik J, Glynn R, et al. Association of visual impairment with mobility and physical function. $\mathcal{F} \mathrm{Am}$ Geriatr Soc 1994;42:287-92.

3 Llewellyn-Jones RH, Baikie KA. Visual impairment and depression in residential care. Med F Aust 1997;167:416.

4 Dargent-Molina P, Favier F, Grandjean H, et al. Fall-related factors and risk of hip fracture: the EPIDOS prospective factors and risk of hip fracture:
study. Lancet 1996;348:145-9.

5 Harries U, Landes R, Popay J. Visual disability among older people: a case study assessing needs and examining services. F Public Health Med 1994;16:211-18. 
6 Finch S, Doyle W, Lowe C, et al. National diet and nutrition survey: people aged 65 years and over. Volume1: Report of the

7 Royal Society of Physicians of London and the British Geriatrics Society. Standardised assessment scales for elderly people. London, 1992 .

8 McGraw PV, Winn B. Glasgow acuity cards: a new test for the measurement of letter acuity in children. Ophthalmic Physiol Opt 1993;13:400-4.

9 Bailey IL, Lovie JE. New design principles for visual acuity letter charts. Am f Optom Physiol Opt 1976;53:740-5.

10 Vaughan D, Asbury T, Riordan-Eva P. General ophthalmology. London: Prentice-Hall, 1992.

11 World Health Organisation. International statistical classifcation of

12 Rubin GS, West SK, Munoz B, et al. A comprehensive assessment of visual impairment in a population of older assessment of visual impairment in a population of older

13 Mantel N, Haenszel W. Statistical aspects of the analysis of data from retrospective studies of disease. $\mathcal{F}$ Nat Cancer Inst data from retrospect

14 Silver JH, Gould ES, Irvine D, et al. Visual acuity at home and in eye clinics. Trans Ophthalmol Soc UK 1978;98:2626.

15 McGraw PV, Winn B, Gray LS, et al. Improving the reliability of visual acuity measures in young children. Ophthalmic Physiol Opt (in press)

16 Lavery JR, Gibson JM, Shaw DE, et al. Vision and visua acuity in an elderly population. Ophthalmic Physiol Opt 1988;8:390-3.

17 Attebo K, Mitchell P, Smith W. Visual acuity and the causes of visual loss in Australia. Ophthalmology 1996;103:357-64.

18 Taylor HR, Livingstone PM, Stanislavsky YL, et al. Visual impairment in Australia: distance visual acuity, near vision and visual field findings of the Melbourne visual impairment project. Am F Ophthalmol 1997;123:328-37.

19 Mitchell P, Hayes P, Wang JJ. Visual impairment in nursing home residents: the Blue Mountains eye study. Med $\mathcal{F}$ Aust 1997;166:73-6.

20 Sturgess I, Rudd AG, Shilling J. Unrecognized visual problems amongst residents of part III homes. Age Ageing 1994; 23:54-6.

21 Salive ME, Guralnik J, Christen W, et al. Functional blindness and visual impairment in older adults from three communities. Ophthalmology 1992;99:1840-7.

22 Klein R, Klein BEK, Lee KP. The changes in visual acuity in a population. Ophthalmology 1996;103:1169-78.

23 Wormald RPL, Wright LA, Courtney P, et al. Visual problems in the elderly population and implications for services. BMF 1992;304:1226-9.

24 Reidy A, Minassian DC, Vafidis G, et al. Prevalence of serious eye disease and visual impairment in a north London population: population based, cross-sectional study. BMf 1998;316:1643-6.

25 Cullinan TR. The epidemiology of visual disability-studies of visually disabled people in the community. Canterbury: University of Kent, 1977.

26 McMurdo MET, Baines PS. The detection of visual disability in the elderly. Health Bull (Edin) 1988;46:327-9.

27 Long CA, Holden R, Mulkerrin E, et al. Opportunistic screening of visual acuity of elderly patients attending outpatient clinics. Age Ageing 1991;20:392-5.

28 Wormald R. Assessing the prevalence of eye disease in the community. Eye 1995;9:674-6.

29 Klein R, Klein BE, Linton KL, et al. The Beaver Dam eye study: visual acuity. Ophthalmology 1991;98:1310-15. 